\title{
Discrete Model Reference Adaptive Control System for Automatic Profiling Machine
}

\author{
Peng Song, Guo-kai Xu, and Xiu-chun Zhao \\ College of Electromechanical and Information Engineering, Dalian Nationalities University, Dalian 116605, China \\ Correspondence should be addressed to Peng Song, spony@dlnu.edu.cn
}

Received 3 December 2011; Revised 15 May 2012; Accepted 6 June 2012

Academic Editor: Yunjun Xu

Copyright () 2012 Peng Song et al. This is an open access article distributed under the Creative Commons Attribution License, which permits unrestricted use, distribution, and reproduction in any medium, provided the original work is properly cited.

\begin{abstract}
Automatic profiling machine is a movement system that has a high degree of parameter variation and high frequency of transient process, and it requires an accurate control in time. In this paper, the discrete model reference adaptive control system of automatic profiling machine is discussed. Firstly, the model of automatic profiling machine is presented according to the parameters of DC motor. Then the design of the discrete model reference adaptive control is proposed, and the control rules are proven. The results of simulation show that adaptive control system has favorable dynamic performances.
\end{abstract}

\section{Introduction}

Automatic profiling machine is a movement system which has a high degree of parameter variation and high frequency of transient process, and it requires an accurate control in time. The traditional linear control methods, such as PID, cannot meet present needs or requirements of advanced performance. The adaptive control not only solves the problem that the control plant cannot be observed directly, but also improved the abilities of resisting interference [1]. The applications of adaptive control to movement system are widespread [2-4], but it is infrequent in automatic profiling machine. A practical adaptive controlling scheme is proposed for automatic profiling machine in [5]. In this paper, a discrete model reference adaptive control (MRAC) method is applied to automatic profiling machine. The discrete control method is convenient for program and contributes to application of adaptive control theory in practice.

\section{The Mathematics Model}

The control system is double closed-loop control system whose current loop is PI control and speed loop is MRAC. The DC motor parameters [6] of automatic profiling machine are shown in Table 1 . The equivalent plant of speed loop is consisted of current loop and motor, and the transfer function is

$$
G(s)=\frac{2377011.5}{s^{2}+2252.87 s+5747.23}
$$

\section{The Design of MRAC System}

The difference equation of the plant is

$$
A\left(z^{-1}\right) y(k)=z^{-1} B\left(z^{-1}\right) u(k),
$$

where

$$
A\left(z^{-1}\right)=1-\sum_{i=1}^{n} \hat{a}_{i} z^{-i}, \quad B\left(z^{-1}\right)=\sum_{i=0}^{m} \widehat{b}_{i} z^{-i},
$$

$y(k)$ and $u(k)$ are the output and input of the plant, respectively; $z^{-1}$ is delay operator; $k$ is the discrete-time variable.

The difference equation of the reference model is

$$
A_{m}\left(z^{-1}\right) y_{m}(k)=z^{-1} B_{m}\left(z^{-1}\right) r(k)
$$

where

$$
A_{m}\left(z^{-1}\right)=1-\sum_{i=1}^{n} a_{i} z^{-i}, \quad B_{m}\left(z^{-1}\right)=\sum_{i=0}^{m} b_{i} z^{-i},
$$




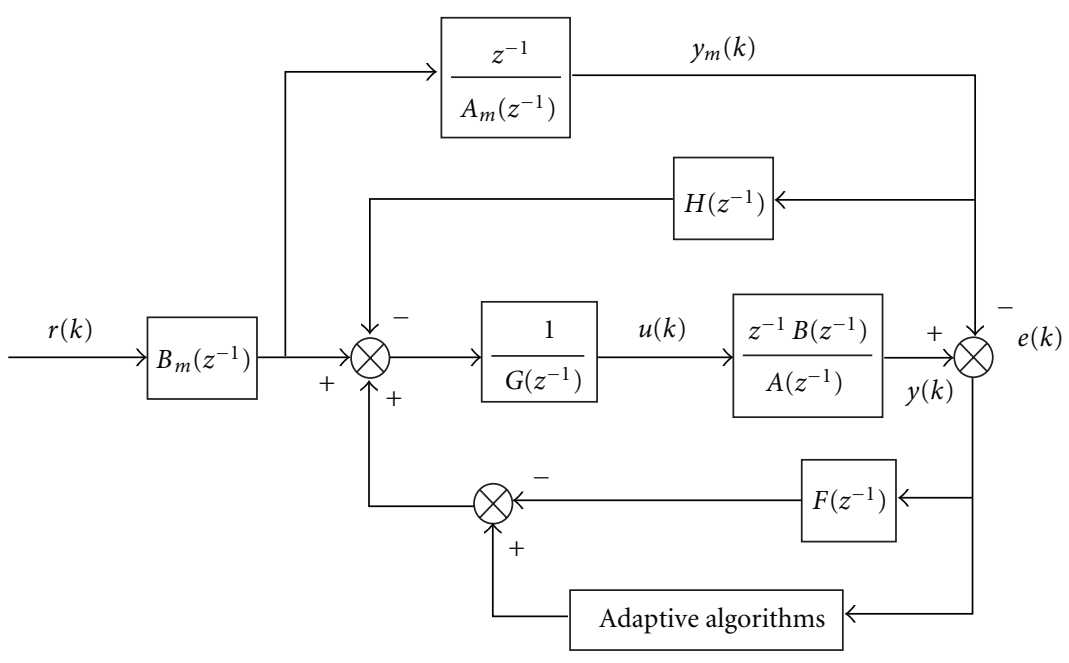

FIGURE 1: Block diagram of MRAC system.

TABLE 1: The parameters of DC motor.

\begin{tabular}{lcc}
\hline Parameter & Unit & Value \\
\hline Rated voltage & $\mathrm{V}$ & 100 \\
Rated current & $\mathrm{A}$ & 6 \\
Rated speed & $\mathrm{r} / \mathrm{min}$ & 1000 \\
Motor constant & $\mathrm{V} / \mathrm{r} / \mathrm{min}$ & 0.1 \\
Electromagnetic time constant & $\mathrm{s}$ & 0.00246 \\
Mechanical time constant & $\mathrm{s}$ & 0.078 \\
\hline
\end{tabular}

$y_{m}(k)$ and $r(k)$ are the output and input of the reference model.

The output error and its prediction are given by

$$
\begin{aligned}
e(k) & =y(k)-y_{m}(k), \\
e^{\circ}(k) & =y^{\circ}(k)-y_{m}(k),
\end{aligned}
$$

where $e^{\circ}(k)$ and the other variables with "o" represent the predictions.

The structure of the adaptive control system is shown in Figure 1 where

$$
\begin{gathered}
H\left(z^{-1}\right)=\sum_{i=1}^{n} h_{i}(k) z^{-i+1} \\
G\left(z^{-1}\right)=\sum_{i=0}^{m} g_{i}(k) z^{-i} \\
F\left(z^{-1}\right)=\sum_{i=1}^{n} f_{i}(k) z^{-i+1}
\end{gathered}
$$

From Figure 1, the following relationship can be obtained $B_{m}\left(z^{-1}\right) r(k)=H\left(z^{-1}\right) y_{m}(k)+F\left(z^{-1}\right) e(k)+G\left(z^{-1}\right) u(k)$.
Introduc (8) into (4):

$$
\begin{aligned}
& A_{m}\left(z^{-1}\right) y_{m}(k) \\
& \quad=z^{-1}\left[H\left(z^{-1}\right) y_{m}(k)+F\left(z^{-1}\right) e(k)+G\left(z^{-1}\right) u(k)\right] .
\end{aligned}
$$

Subtract (9) from (2):

$$
\begin{aligned}
A\left(z^{-1}\right) e(k) & \\
= & {\left[A_{m}\left(z^{-1}\right)-A\left(z^{-1}\right)-z^{-1} H\left(z^{-1}\right)\right] y_{m}(k) } \\
& +\left[z^{-1} B\left(z^{-1}\right)-z^{-1} G\left(z^{-1}\right)\right] u(k) \\
& -z^{-1} F\left(z^{-1}\right) e(k) .
\end{aligned}
$$

According to the Hyperstability theory, the discrete system control laws [1] are

$$
\begin{aligned}
& h_{i}^{I}(k)=h_{i}^{I}(k-1)+\lambda_{i} e(k) y_{m}(k-i), \\
& h_{i}^{P}(k)=\mu_{i} e(k) y_{m}(k-i),
\end{aligned}
$$

where

$$
\begin{gathered}
i=1,2, \ldots, n ; \quad \lambda_{i}>0 ; \quad \mu_{i} \geq-\frac{\lambda_{i}}{2}, \\
g_{i}^{I}(k)=g_{i}^{I}(k-1)+\rho_{i} e(k) u(k-i-1), \\
g_{i}^{P}(k)=\sigma_{i} e(k) u(k-i-1),
\end{gathered}
$$

where

$$
\begin{gathered}
i=1,2, \ldots, m ; \quad \rho_{i}>0 ; \quad \sigma_{i} \geq-\frac{\rho_{\mathrm{i}}}{2}, \\
f_{i}^{P}(k)=q_{i} e(k) e(k-i), \\
f_{i}^{I}(k)=f_{i}^{I}(k-1)+l_{i} e(k) e(k-i),
\end{gathered}
$$

where

$$
i=1,2, \ldots, n ; \quad l_{i}>0 ; \quad q_{i} \geq-\frac{l_{i}}{2}
$$




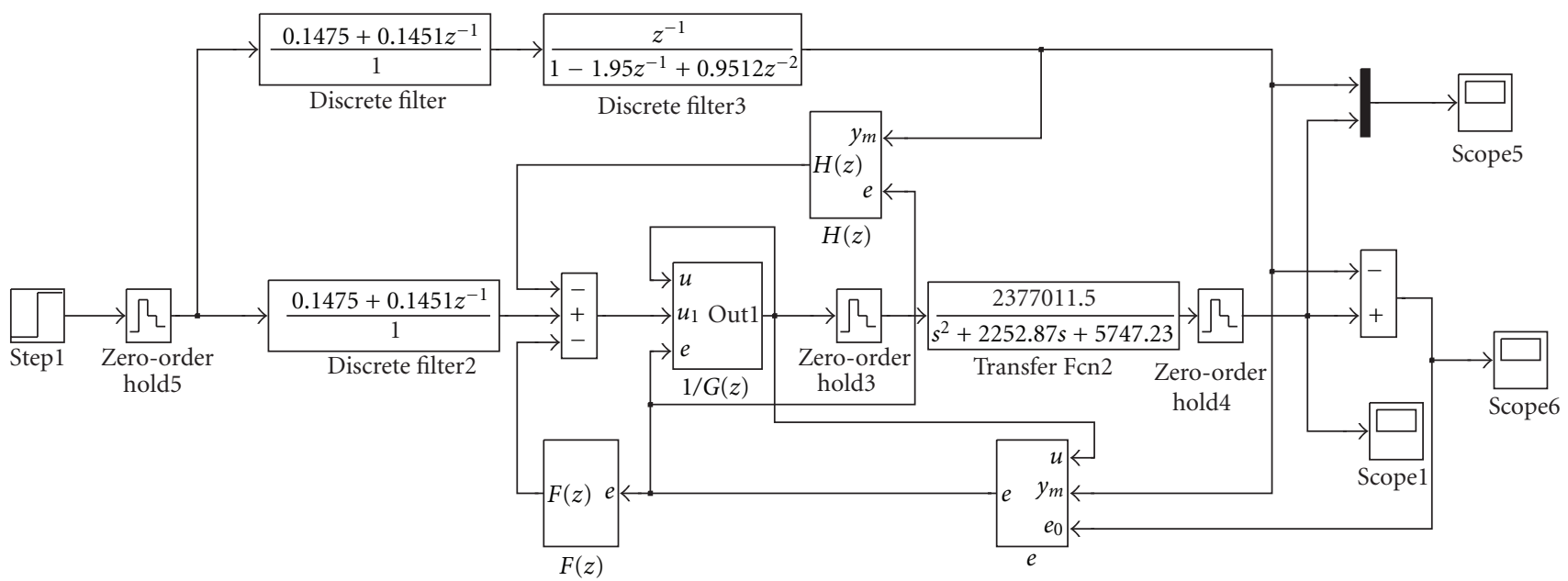

FIgURE 2: Simulation block diagram of MRAC system.

$E(k)$ cannot be found directly in the operations above, so it can be replaced by $e^{\circ}(k)$. According to (10), $e(k)$ becomes

$$
\begin{aligned}
e(k)= & \sum_{i=1}^{n}\left[\hat{a}_{i}-f_{i}(k)\right] e(k-i) \\
& +\sum_{i=1}^{n}\left[a_{i}-a_{i}-h_{i}(\hat{k})\right] y_{m}(k-i) \\
& +\sum_{i=0}^{m}\left[\hat{b}_{i}-g_{i}(k)\right] u(k-i-1) .
\end{aligned}
$$

The prediction error can be gained:

$$
\begin{aligned}
e^{\circ}(k)= & \sum_{i=1}^{n}\left[\hat{a}_{i}-f_{i}^{I}(k-1)\right] e(k-i) \\
& +\sum_{i=1}^{n}\left[a_{i}-a_{i}-h_{i}^{I}(\hat{k}-1)\right] y_{m}(k-i) \\
& +\sum_{i=0}^{m}\left[\hat{b}_{i}-g_{i}^{I}(k-1)\right] u(k-i-1) .
\end{aligned}
$$

Subtract (16) from (15) and link (11) (13); the function becomes

$$
\begin{aligned}
e(k)-e^{\circ}(k)=- & {\left[\sum_{i=1}^{n}\left(l_{i}+q_{i}\right) e^{2}(k-i)\right.} \\
& +\sum_{i=0}^{n}\left(\lambda_{i}+\mu_{i}\right) y_{m}^{2}(k-i) \\
& \left.+\sum_{i=0}^{m}\left(\rho_{i}+\sigma_{i}\right) u^{2}(k-i-1)\right] e(k) .
\end{aligned}
$$

Equation (17) becomes (18) by calculating,

$$
e(k)=\frac{e^{\circ}(k)}{\left(1+\sum_{i=1}^{n}\left(l_{i}+q_{i}\right) e^{2}(k-i)+\sum_{i=0}^{n}\left(\lambda_{i}+\mu_{i}\right) y_{m}^{2}(k-i)+\sum_{i=0}^{m}\left(\rho_{i}+\sigma_{i}\right) u^{2}(k-i-1)\right)} .
$$

\section{Simulation Studies}

The reference model takes the form as follows:

$$
\frac{z^{-1} B_{m}\left(z^{-1}\right)}{A_{m}\left(z^{-1}\right)}=\frac{0.1475 z^{-1}+0.1451 z^{-2}}{1-1.95 z^{-1}+0.9512 z^{-2}} \text {. }
$$

Make simulation according to the analysis above by SIMULINK. The structure of the adaptive control system is shown in Figure 2, and the parameters value are shown in Table 2.
The simulation results are shown in Figures 3-5. To make a calculation, the percentage overshoot is $6 \%$, the rise time is $1 \mathrm{~s}$, the settling time is $2 \mathrm{~s}(\Delta=0.02)$. Figure 3 is shown that the maximal error value is less than $40 \mathrm{r} / \mathrm{min}$, so the control plant could better track reference model. Input the interference signal into the front of plant transfer function between $10 \mathrm{~s}$ and $20 \mathrm{~s}$. The simulation results (in Figure 4) indicate that the control plant could be stable in 2 seconds. Input white noise into the reference input of plant not the reference input of model, and the result is shown in Figure 5. 


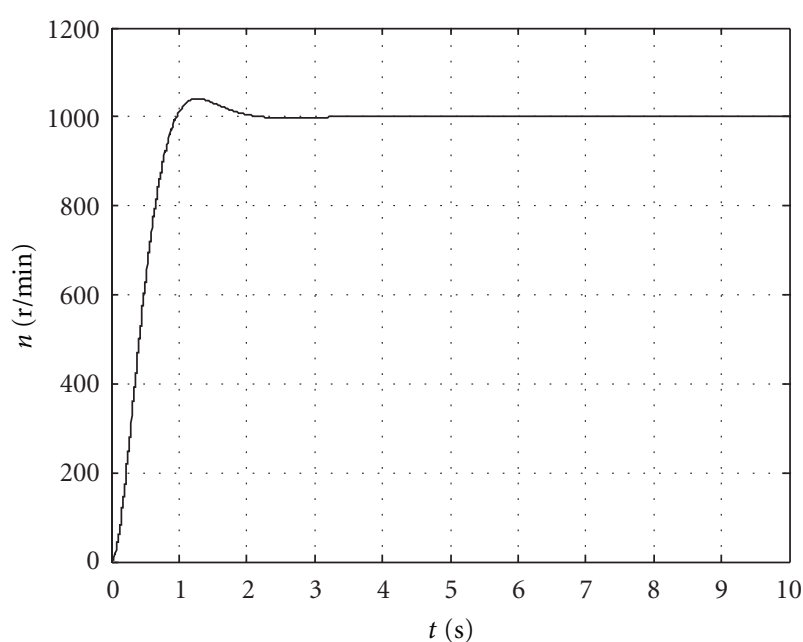

(a) Reference model

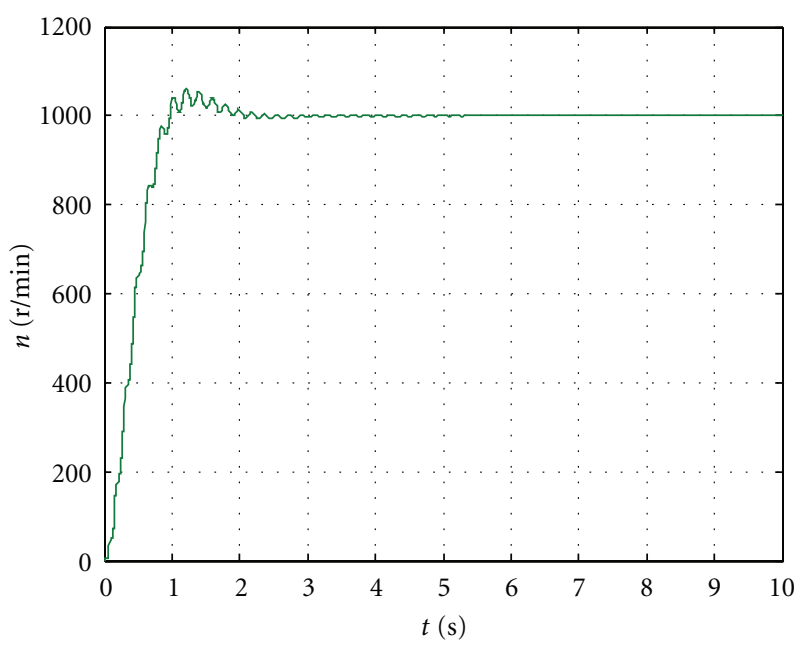

(b) Control plant

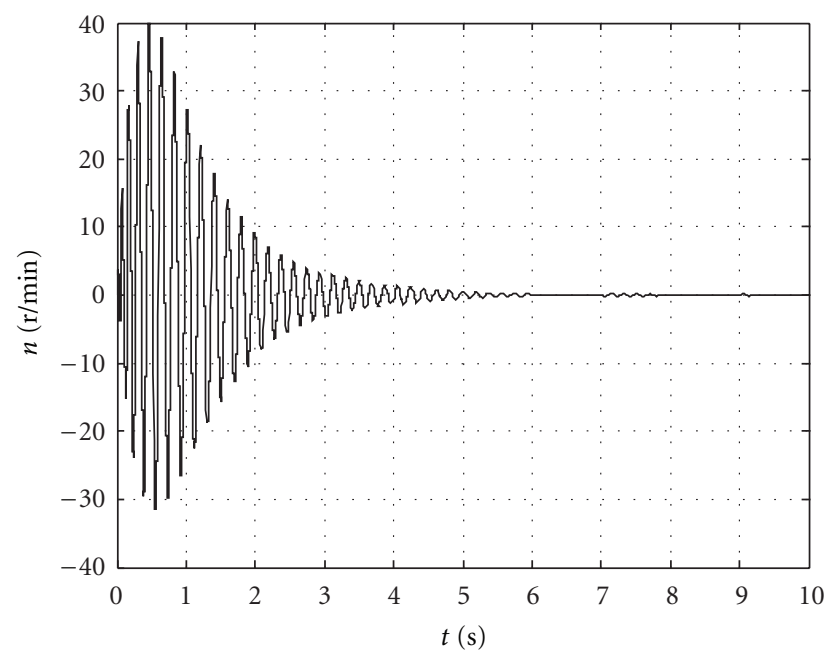

(c) Error figure

Figure 3: Output figures of simulation.

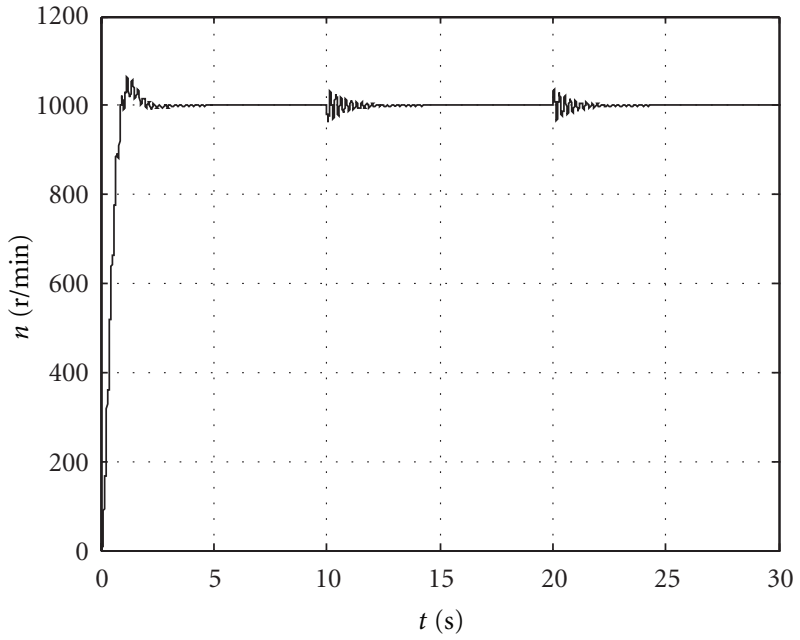

(a) Control plant

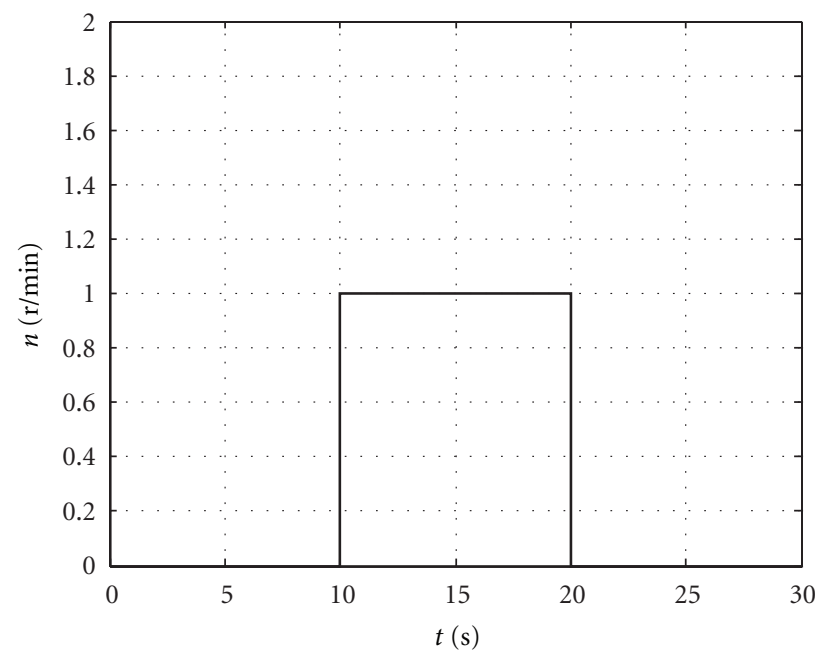

(b) Interference signal

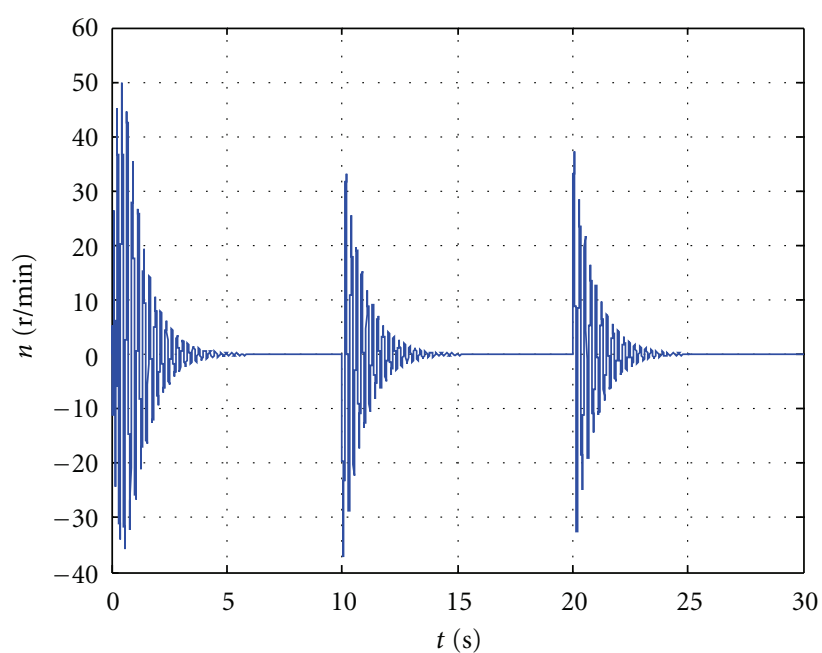

(c) Error figure

FIgURE 4: Output figure with interference signal. 


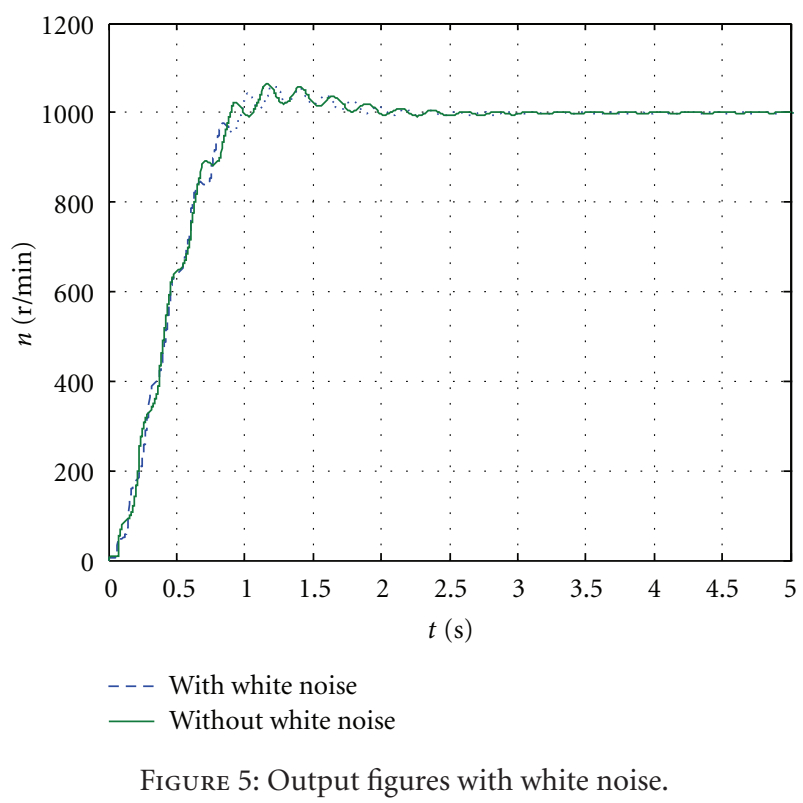

TABLE 2: Parameter values of MRAC system.

\begin{tabular}{lccc}
\hline Parameter & Value & Parameter & Value \\
\hline$h_{1}^{I}(0)$ & 0 & $h_{2}^{I}(0)$ & 0 \\
$\lambda_{1}$ & 0.1 & $\lambda_{2}$ & 0.01 \\
$g_{1}^{I}(0)$ & 1 & $g_{2}^{I}(0)$ & 0 \\
$\rho_{1}$ & 3000 & $\rho_{2}$ & 0.01 \\
$f_{1}^{I}(0)$ & 0 & $f_{2}^{I}(0)$ & 0 \\
$l_{1}$ & 1 & $l_{2}$ & 0.1 \\
\hline
\end{tabular}

Obviously the figure has no visible variation. So the control system has better abilities of resisting interference.

\section{Conclusion}

The discrete model reference adaptive control system of automatic profiling machine is discussed in this paper. The results of simulation show that adaptive control system has favorable dynamic performance. The discrete design method is easy to realize by computer. The work in this paper will lay a foundation for the application of adaptive control in practice.

\section{Acknowledgments}

This paper was supported by the National Science and Technology Support Program Project (2009BAH41B05) and the Fundamental Research Funds for the Central Universities.

\section{References}

[1] S. C. Wu and Z. Q. Wu, Adaptive Control, China Machine Press, Beijing, China, 2005.

[2] G. K. Xu and X. C. Zhao, The Adaptive Control of Drive System For HS2000 Electric Vehicle, The Research and Development of China Electric Vehicle, Beijing Institute of Technology Press, Beijing, China, 2005.
[3] P. Song, W. Q. Long, G. K. Xu, and X. C. Zhao, "Research on discrete-time model reference adaptive control of electric vehicle driven motor," Journal of System Simulation, vol. 19, no. 18, pp. 4261-4264, 2007.

[4] G. K. Xu, L. R. You, X. C. Zhao, P. Song, and C. H. Liu, "A research on adaptive speed controller of a $4 \mathrm{M}$ gantry planning machine," Control Theory and Applications, vol. 24, no. 5, pp. 846-850, 2007.

[5] L. R. You, F. Qiao, and G. K. Xu, "Adaptive controller for automatic profiling machines," Control Theory and Applications, vol. 21, no. 6, pp. 1025-1028, 2004.

[6] G. K. Xu, Z. Y. Chu, and S. C. Wu, The Adaptive Controller Design For Movement System, Chinese Technology Press, Beijing, 2004. 

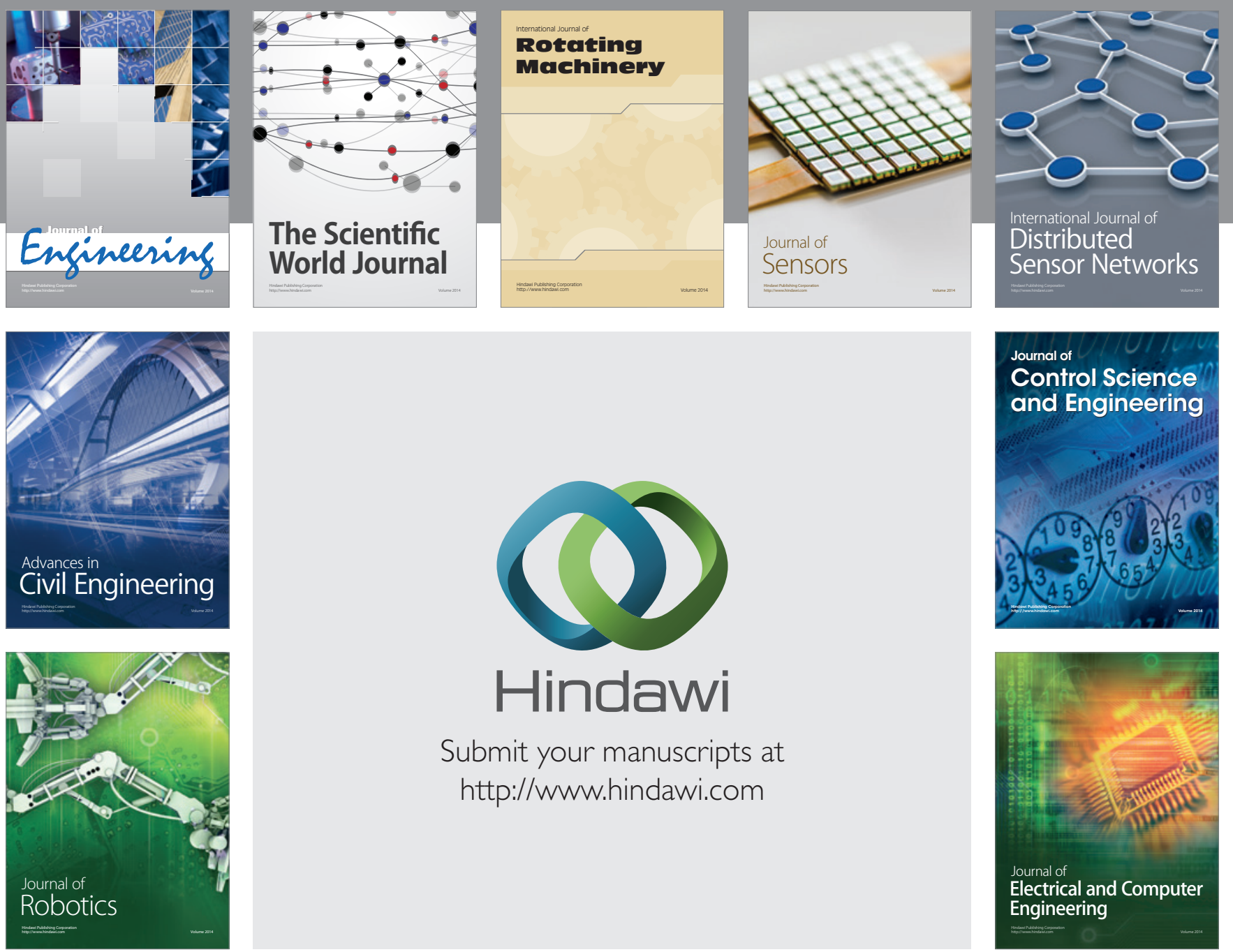

Submit your manuscripts at

http://www.hindawi.com
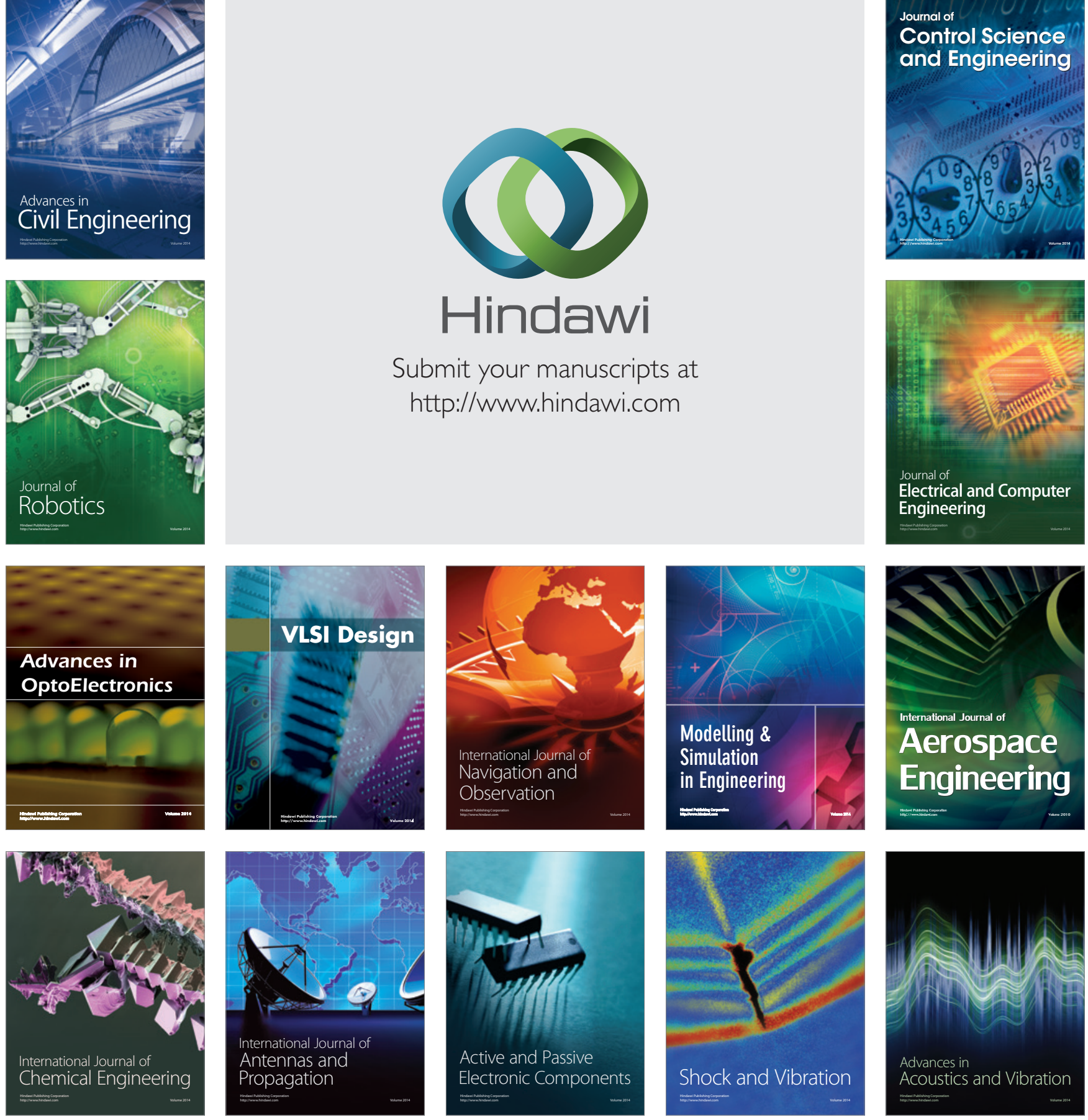